\title{
A (RE)VOLTA DA DIALÉTICA: DIÁLOGO, AUTOCRÍTICA E TRANSFORMAÇÃO NO PENSAMENTO DE LEANDRO KONDER
}

\author{
André Luis de Oliveira Mendonça \\ é doutor em Filosofia e professor adjunto do Instituto de Medicina Social (IMS) da Universidade \\ Estadual do Rio de Janeiro (Uerj).Rio de Janeiro,RJ.Brasil.E-mail: <alomendonca@gmail.com> \\ Katia Reis de Souza \\ é doutora em Saúde Pública e pesquisadora do Centro de Estudos da Saúde do Trabalhador e \\ Ecologia Humana (Cesteh), Escola Nacional de Saúde Pública (Ensp) da Fundação Oswaldo Cruz \\ (Fiocruz).Rio de Janeiro, RJ.Brasil.E-mail: <katreis@ensp.fiocruz.br> \\ http://dx.doi.org/10.1590/0102-089108/101
}

Contudo, valeu a pena ter brigado por coisas nas quais eu acreditava, mesmo que o preço fosse o fracasso. A ética me consolou nas derrotas. E eu sempre me lembrava de que, afinal (mal comparando), Antonio Gramsci e Walter Benjamim também foram losers.

LEANDRO KONDER

Leandro Konder foi, ao lado de Carlos Nelson Coutinho, Michael Löwy (radicado na França desde 1969) e Marilena Chaui, entre outros intelectuais de esquerda com inclinação mais filosófica, um dos maiores estudiosos do marxismo no Brasil. Foi professor, filósofo, jornalista, advogado, escritor e até poeta. Consoante Secco (2002, p. 103), Konder foi um intelectual no sentido pleno da palavra: "um apaixonado pelas ideias". Além disso, ele foi, ousemos dizer, um intelectual orgânico na acepção de Gramsci: seu comportamento pessoal, notavelmente amável e gentil, não o impediu de travar a batalha das ideias nos mais diversos campos e 
temáticas, sendo sempre, porém, incisivo e aguerrido, contra a dominação, a opressão e a repressão, como bem cabe a um intelectual comunista do seu porte. Tanto assim que a obra coletiva Leandro Konder: a revanche da dialética, que consiste em um consistente perfil intelectual do nosso autor, resultante da "VI Jornada de Estudos das Ciências Sociais", deslinda o fato de a obra de Konder ter mostrado, entre outras coisas, a grandeza, a atualidade e a dimensão humanizadora do marxismo, tal como explicita na apresentação Maria Orlanda Pinassi, organizadora do livro (2002).

As primeiras produções bibliográficas de Leandro Konder foram divulgadas no início dos anos 1960. Dentre elas, as mais significativas foram publicadas na revista Estudos Sociais, editada por um grupo de intelectuais de esquerda. De acordo com Coutinho (2002), deve-se a Konder o ingresso no Brasil de autores do campo do marxismo ocidental, como Gramsci. É digna de menção a importante 90 participação de Konder - juntamente com Carlos Nelson Coutinho - na publicação de Concepção dialética da história (Gramsci, 1986), além de ter exercido protagonismo na recepção e divulgação das ideias gramscianas no Brasil. A propósito, logo na abertura da "Nota sobre Gramsci" de apresentação ao referido livro, seus autores - Carlos Nelson e Konder - afirmam que "Este é o primeiro livro de Antonio Gramsci publicado no Brasil”; ou seja, aqui, a publicação dos Cadernos (Gramsci, 2000) começou a sair após duas décadas de seu aparecimento na Itália levada a termo por Palmiro Togliatti, então um dos dirigentes do Partido Comunista Italiano, graças ao pioneirismo protagonizado por Konder.

Convém observar que, até o início dos anos 1960, era quase inexistente o tratamento teórico-filosófico do marxismo por autores brasileiros (Coutinho, 2002). Konder publicou, em 1965, o livro intitulado Marxismo e alienação, que, para Coutinho, introduz um tema filosófico até então completamente ignorado no Brasil pelo pensamento de 
esquerda: o conceito de alienação em Marx, como o próprio título já sugere. Infelizmente, esse e outros livros de Konder estão esgotados e não foram reeditados. De todo modo, por certo, sua produção se afirma como sendo um marco de inflexão na história do marxismo no Brasil, tal como reconhece Secco (2002). Constata-se nas suas obras forte empenho em interpretar as categorias teóricas marxistas a partir da análise da realidade e dos fatos ocorridos na nossa história. Nas palavras do próprio Konder, suas obras tiveram como objetivo precípuo reconstituir e atualizar "a fisionomia intelectual do filósofo Karl Marx” (Konder, 1984, p. 139).

Impõe-se a ressalva de que, embora as obras de Konder tratem, invariavelmente, do materialismo histórico e seus defensores, não se considera que seus textos sejam simples comentários acerca dessa corrente libertária de pensamento. Defende-se, aqui, a proposição de que ele desenvolveu um modo peculiar de apreensão das ideias e ideais concernentes a essa tradição filosófica, tarefa que realizou livre de academicismos e de hermetismo.

Conquanto Konder tenha abordado praticamente todas as temáticas e conceitos relativos à tradição marxista, observa-se em suas publicações a preocupação central com a questão da dialética, ou melhor, com o "método" do materialismo histórico e dialético. Konder (1988) advoga a tese de que ocorreu certo menosprezo atinente ao emprego da dialética como método no materialismo histórico latino-americano em geral e brasileiro em particular, tanto no modo de pensar a realidade quanto na forma de intervir sobre ela, o que levou a perdas significativas no campo da reflexão filosófica e na concretude dos eventos históricos; ecoando, desse modo, a tese defendida por Lukács (2012), um dos marxistas que mais o influenciou, no seu clássico História e consciência de classe. Com efeito, logo no primeiro capítulo, como seu próprio título "O que é marxismo ortodoxo?" 
indica, Lukács (2012) advoga a tese de que, se há uma ortodoxia no marxismo, esta tem a ver com o método dialético. Dialogando criticamente com os chamados revisionistas, Lukács desenvolve o argumento segundo o qual dois são os pontos nevrálgicos do materialismo histórico-dialético: um é o da totalidade concreta da realidade em oposição ao reducionismo economicista, o outro é o da ação revolucionária contrária ao etapismo ou determinismo histórico. Vindo a se tornar uma das obras mais influentes da história do marxismo, História e consciência de classe não foi bem recebida pelo Partido Comunista da URSS de então, muito provavelmente por ser incompatível com o "semipositivismo" reinante entre os líderes do Comintern; por intermédio do conceito de consciência de classe, Lukács atribuiu papel decisivo à dimensão subjetiva do proletariado, frente às ditas "condições objetivas", no processo revolucionário. Tendo respondido aos seus críticos logo em seguida, o fato 92 é que a réplica de Lukács só veio a lume no ano de 1996, em Budapeste (traduzido aqui, em 2015, como Reboquismo e dialética, o livro conta com uma contextualização assaz elucidativa de Michael Löwy acerca da sua não publicação anterior e com um posfácio de Nicolas Tertulian).

Cabe-nos ainda, inicialmente, uma rápida observação relativa ao ponto de vista do autor em tela a respeito dos instrumentos conceituais do marxismo. Konder enfatiza que as categorias de análise do materialismo dialético estão demasiadamente ligadas às circunstâncias da sociedade em que vivia o autor de $O$ capital. Trata-se de construções teóricas com características que somente podem ser adequadamente compreendidas em conexão com seu tempo. Em que pese o caráter universal do modo de produção capitalista, o fato é que a capacidade de compreender os problemas em profundidade depende, decerto, do nível de amadurecimento que os problemas alcançam na realidade e das lentes de que se lança mão para o seu exame. O legado filosófico marxista, 
conforme assevera Konder (1992), contribui com categorias analíticas essenciais para a interpretação dos problemas, necessitando ser reexaminado e redimensionado no tempo presente: "não podemos ler Marx nos transportando artificialmente para o tempo dele. Vivemos uma história que ele não viveu, vimos coisas que ele não viu, temos preocupações que ele não tinha” (Konder, 1992, p. 56).

Nosso foco pretende lançar luz acerca do conceito de dialética, mais precisamente à tese konderiana cujo conteúdo essencial é o de que a dialética fora derrotada devido à falta de pendor para a reflexão teórica genuína e de capacidade de autocrítica e autotransformação por parte de segmentos de esquerda, bem como pelo abandono da práxis revolucionária. No que se segue, discorremos sobre a dialética como diálogo e autocrítica; na sequência, tratamos da ideia de transformação a partir das categorias de práxis e história; e por fim, defendemos a pertinência de buscar inspiração na obra de Konder, de modo a pensar sobre a conjuntura atual.

\section{0 que é a dialética, afinal? Diálogo, autocrítica e transformação}

Na tradição plural e dinâmica do materialismo histórico, existem várias concepções distintas, e até mesmo concorrentes, acerca do sentido e significado da dialética; acepções que são, elas mesmas, fruto de um processo dialético. Nesse sentido, nós fazemos a aposta de que a questão central reside na rediscussão do método dialético em perspectiva histórica, tomando a própria dialética como princípio inspirador da nossa abordagem; ou seja, precisamos lançar mão da dialética para examinar criticamente a própria dialética. Ou ainda, em uma palavra, devemos caminhar em direção a uma espécie de "dialética da dialética", tal como, à sua maneira, fez o próprio Konder.

A perspectiva filosófica de Leandro Konder confere atualidade ao "método" do materialismo dialético. Em $A$ 
derrota da dialética (1988), conforme já destacado, Konder apresenta um ângulo de compreensão assaz original que coloca em relevo fatores ligados à história do socialismo no cenário mundial, em conjugação com aspectos característicos da vida social e cultural do nosso país. A tese defendida por Konder, na referida obra, põe em evidência o fato de que o pensamento de Marx - tal como foi trazido para o Brasil e assimilado pelo nascente marxismo brasileiro "sofreu a perda de sua dimensão dialética" (Konder, 1988, p. 52). Dimensão essa que exige que sejam observados os desdobramentos práticos e as implicações políticas de sua filosofia. O argumento levado a efeito por Konder diz respeito, sobretudo, ao fato de que as concepções de Marx pressupunham certo nível de experiência política e certo nível de organização do movimento operário, como aqueles encontrados nos países industrializados da Europa, à época de Marx.

O ponto que chama atenção, na explanação formulada por Konder, é a afirmação de que o aporte teórico marxista teria sido pensado em função de determinadas condições materiais da história concreta e se reportava a pessoas que sentiam e vivenciavam os problemas a elas relacionados, sobretudo a classe operária. Na sua perspectiva, o proletariado é reconhecidamente a classe protagonista das mudanças sociais; portanto, caberia a ele uma atuação política central na história. Desse modo, Konder manifesta desconforto em fazer uso das concepções de Marx de forma meramente "escolástica" ou retórico-especulativa, estranha às preocupações teóricas centrais em que foram engendradas (Konder, 1988, p. 53).

Não obstante os diferentes caminhos e configurações que o marxismo assumiu no Brasil e na América Latina, o fato é que, para Konder, o método dialético - a seu ver essencial à perspectiva filosófica de Marx - foi se ofuscando e, ao deixar de fazer parte do seu aporte filosófico, essa 
corrente de pensamento (o marxismo) perdeu a capacidade de enxergar, com maior nitidez, as contradições que constituem o tecido social da realidade. Ao final da "Nota preliminar sobre a dialética", Konder expõe o problema que será investigado por ele:

Essa característica da perspectiva de Marx (genuína prática teórica e 'fluidificação' dos conceitos, tendo em vista a luta revolucionária) tornava-a apta para despertar um forte interesse e uma imensa simpatia nos espíritos mais agudamente rebeldes, no mundo inteiro: tais espíritos se aproximavam do pensamento de Marx na expectativa de o utilizarem, em seus esforços para uma concretização revolucionária eficaz no ímpeto rebelde. Contudo, na medida em que tal perspectiva permanecia vaga e se apoiava em ideias insuficientemente esclarecidas ou deficientemente aprofundadas, elas não podiam deixar de se defrontar com múltiplas dificuldades (dificuldades essas que serão justamente o objeto da tese) (Konder, 1988, p. 15).

Konder parte da assunção de acordo com a qual os preceitos do método dialético marxista devem se afastar das acentuadas formalizações de caráter positivista e/ou evolucionista, devendo ater-se à complexidade da materialidade da vida social por meio da reflexão crítica e do permanente contato com o proletariado (Konder, 1988). Ademais, o método do materialismo dialético deve suscitar a renovação da teoria no estreito contato com uma realidade que lhe é, permanentemente, singular e inédita. Identifica-se uma crítica nas obras de Konder (1988; 2004) relativa ao reducionismo e empobrecimento do uso da dialética marxista ao esquema da tríade hegeliana "tese-antítese-síntese" (Konder, 1988, p. 146), ou ainda à adoção de instruções e fórmulas teóricas importadas, destituídas de crítica. 
A ideia predominante encontrada nas obras de Konder $(1988 ; 2010)$ diz respeito ao argumento acerca da necessidade de se reaver a dimensão filosófica das ideias de Marx por meio do revigoramento do método dialético de interpretação da história. Nele, o sujeito assume papel fundamental no processo de construção do conhecimento: "O sujeito transforma a si mesmo e transforma historicamente o mundo. Esse movimento jamais é apreendido por cientistas que pregam a pseudoneutralidade metodológica" (Konder, 2010, p. 7). Em outra passagem, ele complementa sua definição de dialética "o modo de pensarmos as contradições da realidade, o modo de compreendermos a realidade como essencialmente contraditória e em permanente transformação" (Konder, 2004, p. 8).

Encontra-se, nas obras de Konder (1984; 1988; 2004), referências a uma dialética interessada na vida 96 material prática como a observação de que na "batalha das ideias" o pensamento de esquerda marxista, contestador da ordem vigente, precisa desenvolver, dialeticamente, suas razões teóricas, investindo na interlocução com aqueles que precisam ser convencidos e não devendo ser considerados como inimigos que precisam ser rapidamente "destroçados". Partindo desse preceito, a acepção de dialética é essencialmente diálogo, e deve se edificar sobre bases de convivência genuinamente democráticas. À luz dos escritos konderianos, confirmam-se importantes aspectos do método do materialismo dialético, entre eles, o necessário reconhecimento de que nunca se deve esquecer que a palavra dialética possui a mesma origem etimológica da palavra diálogo. Konder (1992) desenvolve o "juízo categórico" de que o diálogo possibilita um processo reflexivo por meio do exercício da crítica e da autocrítica: "Torna-se imperioso respeitar o outro" (Konder, 1992, p. 139). 
Conforme a afirmação do autor, o sujeito (no processo de conhecimento) se realiza na intersubjetividade por meio de um esforço para melhor compreensão mútua: "as razões do outro podem me proporcionar uma ocasião significativa para ampliar meus horizontes, arejar meu pensamento, fundamentar com maior solidez meu ponto de vista" (Konder, 1992, p. 139). Decerto, o exercício do diálogo abre espaço para conhecimentos novos e ajuda a evitar que se percam reflexões e pensamentos críticos desmistificadores a respeito das contradições sociais. Todavia, Konder (1984) evidencia a interpretação de que a dialética marxista deve ser uma filosofia que gera crítica e questionamento contumaz. Com tom espirituoso que lhe era peculiar, afirma que se trata de uma filosofia que deve continuar a ser "irritante, mesmo" (Konder, 1984, p. 41). Em se tratando da categoria crítica na vertente do método dialético, convém lembrar ainda que Konder (1984), citando Marx, enfatiza a ideia de que se deve manter vivo o espírito da crítica, de modo que se faça valer o pensamento de que ela (a crítica) não pode recuar diante de nada que existe.

Konder (1984) destaca a consideração do autor de O capital a respeito da importância de se cultivar, com o mesmo empenho e compromisso, a capacidade de autocrítica, já que se deve incorporar o negativo à consciência dialética, ou seja, a negação e a suspeita de tudo. Em suas palavras, a dialética marxista "precisa estar sempre disposta a se questionar a si mesma, a se reformular em seus próprios fundamentos, para não se desligar do fluxo da história" (Konder, 1988, p. 13). Historicamente, na avaliação de Konder, a dialética enquanto autocrítica sofreu derrota acachapante com o advento do chamado marxismo-leninismo em sua versão stalinista, porquanto houve uma negação da autotransformação em função do enrijecimento doutrinário 
cristalizado na figura do comissário (profissional do partido); de modo que o dogmatismo partidário não era mais capaz de dar conta da abundância do real. E fora justamente o stalinismo que prevaleceu no interior do ideário de fundação e consolidação do Partido Comunista do Brasil (PCB) e da esquerda marxista em geral ao longo da primeira metade do Século XX.

Do exposto até aqui, nota-se a centralidade das noções de diálogo e autocrítica na argumentação desenvolvida por Konder acerca da dialética. Noções essas que ainda não abarcam toda a riqueza do conceito, que deve ser complementado pela ideia de transformação. Sendo assim, voltamo-nos para a ideia de transformação da realidade por meio da categoria de práxis.

\section{Práxis: Mudar o mundo pela ação coletiva organizada}

Verifica-se, nas obras de Konder (1984; 1988), a práxis como categoria central da dialética marxista. Konder (1988; 2010) destaca o entendimento de que a práxis em Marx vai além do trabalho. E Marx reconheceu isso muito claramente em uma passagem do primeiro volume de $O$ capital (Marx, 2013), quando escreveu sobre a necessidade de vir a ser sempre encurtada a jornada de trabalho, já que a plena liberdade para o homem nunca poderia se realizar inteiramente no âmbito de sua atividade laborativa. De acordo com Marx, o reino da liberdade só começa, de fato, onde cessa o trabalho determinado pela necessidade e pela finalidade externa; portanto, fica além da esfera da produção material (Konder, 1988). Em suas reflexões, Konder coloca a questão do "tempo livre" como importante debate a ser travado no âmbito da organização do trabalho (Konder, 1984), um dos temas mais polêmicos nas discussões arroladas sobre o trabalho.

Konder (1988) afirma que Marx, em especial nas teses sobre Feuerbach (Marx e Engels, 1986), inaugura uma nova razão pela vertente dialética, por meio da qual 
se passa a enxergar o ser humano como um ser essencialmente ativo, que transforma o mundo e a si mesmo simultaneamente. De fato, se tomarmos como base de análise as teses formuladas por Marx e Engels em A ideologia alemã (escrita entre os anos de 1845 e 1846) confirma-se, no texto, a predominância do tema práxis como questão fundamental. A segunda tese sobre Feuerbach exprime, muito bem, a essência da categoria práxis no pensamento marxista:

A questão de saber se cabe ao pensamento humano uma verdade objetiva não é uma questão teórica, mas prática. É na práxis que o homem deve demonstrar a verdade, isto é, a realidade e o poder, o caráter terreno do seu pensamento. A disputa sobre a realidade ou não-realidade do pensamento isolado da práxis - é uma questão puramente escolástica (Marx e Engels, 1986, p. 12).

Nessa vertente teórica, a ação transformadora tem de ser rigorosa, precisa e oportuna. Por isso, identifica-se nos textos konderianos a repetição da ideia de que a práxis necessita da teoria para seu permanente esclarecimento e orientação. Não se pode perder de vista a ideia fundamental da concepção materialista da história, que reconhece o poder do sujeito coletivo de tomar iniciativas e fazer escolhas; porquanto, depende-se de valores que permitam o empenho em projetos de transformação do mundo na criação de um tipo melhor de sociedade, em um futuro pelo qual valha a pena lutar, já que o mercado "cultiva um espírito ultra competitivo que fere a sensibilidade das pessoas, endurecendo seus corações: são os valores que fazem um operário politizado levantar da cama de madrugada para participar de uma greve" (Konder, 2010, p. 16).

A expressão "queremos mudar o mundo" constitui-se em uma importante manifestação que se destaca em 
A derrota da dialética (Konder, 1988). Na interpretação do autor, o último século foi manifestamente tempo de insatisfação e inconformismo. Exatamente igual ocorre no campo filosófico: tem-se a impressão de que faltam instrumentos teóricos adequados à interpretação da realidade. Não obstante essa constatação, na linha de pensamento de Konder (1988), deve servir ao aprofundamento, em termos conceituais, da crítica e da "negação" da sociedade tal qual ela está organizada, por meio do emprego do aporte do materialismo dialético. Portanto, deve-se criar categorias mais correspondentes às nossas exigências, para que, ao fim, reorganize-se a vida baseada em um novo modelo de sociedade (Konder, 2001).

$\mathrm{Na}$ genealogia filosófica do materialismo dialético, a que Konder se filia, sobressai a ideia de "consciência revolucionária e postura rebelde" (Konder, 1988, p. 20). Trata-se, consoante o autor, de uma força decisiva para aqueles 100 que não se adaptam ao mundo e persistem em adaptar o mundo a eles. $\mathrm{O}$ autor afirma que quanto mais contraditório se apresenta o processo histórico, mais complexas são as tarefas de transformação consciente da sociedade, tanto mais necessária se torna a chama de rebeldia, para que as contradições não se concretizem. De acordo com as afirmações de Konder (1984), sofremos todos a brutal pressão do mercado hipercompetitivo que nos joga constantemente uns contra os outros, e, por isso, justifica-se a necessidade de nos unirmos a outros seres humanos para mudar o mundo (Konder, 1984); afinal, a atual situação não se constitui como mero acaso. Em verdade, a ordem em que se acha disposta a realidade corresponde a interesses poderosos que se acumpliciam com o peso do passado; por conseguinte, é preciso enfrentá-los e agir, pois, na perspectiva da dialética marxista, as ações de caráter revolucionário "devem extrair sua poesia do futuro, e não do passado" (Konder, 1984, p. 74). 
Distingue-se no pensamento do autor de A derrota da dialética a premissa de que o presente não é inexorável e nem engendra automaticamente o futuro, através de uma dinâmica fatal ou espontânea. O fato é que, conforme a interpretação dialética prevalecente nas obras de Konder, "o futuro precisa lutar para nascer, precisa enfrentar criticamente o presente" (Konder, 1988, p. 20).

Konder (1988) nos adverte acerca do fato de que os revolucionários são seres formados pela própria sociedade que estão negando; de modo que estão marcados pelo mundo que desejam modificar. A postura rebelde é marcada pelo inconformismo, sendo desafiada a se articular com um coletivo, ou seja, com outros rebeldes para uma ação conjunta, contínua, duradoura e de caráter político. Aqui cabe a observação decisiva do caráter indissociável, como aspecto do método dialético, entre teoria e prática política.

\section{A história e os sujeitos que a fazem}

Que homens, afinal, fazem a história? Todos? Alguns? Ou apenas um herói, um espirito iluminado, em cada geração, em cada povo? (Konder, 2002, p. 24).

De acordo com Konder, o terreno em que o modo de pensar dialético proposto por Marx é capaz de demonstrar toda a sua força é, certamente, o da história, o da atividade dos sujeitos humanos. Konder chama atenção para se ter prudência ao se adotar a concepção de história na vertente de Marx, já que se constata nessa tradição de pensamento, no Brasil, uma forte tendência de interpretação pelo enfoque econômico, reduzindo-a, amiúde, ao determinismo economicista.

Na linha da dialética materialista, Konder (1988) defende o imprescindível rigor teórico para identificação dos problemas concretos, tendo como desígnio fundamental a sua 
resolução, o que o coloca irmanado à ideia de dialética do concreto de Kosik (2010). No entanto, ele reafirma (Konder, 2002) a concepção segundo a qual para que as ideias sejam executadas são necessários seres humanos que ponham em movimento a força prática de modificação da história.

No que tange à relação entre história, política e teoria - elementos essenciais de uma interpretação materialista e dialética da história -, Konder recorda a Revolução Russa (de novembro de 1917) como marco político e teórico do pensamento marxista. Em sua avaliação (Konder, 1988), pode-se afirmar que a partir dela (da Revolução) houve ampla difusão das ideias de Marx no Brasil, tendo como principal centro de influência o PCB (fundado em 1919). No entanto, Konder ressalta que o encantamento exercido pelo recém-criado Estado comunista levou as teorias de Marx a uma relativa penumbra e a uma provável "derrota no Brasil”, conforme já mencionado (Konder, 1988, p. 117).

Merece atenção também a observação de Konder de que a concepção do materialismo dialético de história não implica a completa negação da dimensão de continuidade da história. O que ela nos apresenta de inédito é o novo modo de considerarmos a relação entre continuidade e descontinuidade (Konder, 1988). Ao destacar a ideia de que o modo de produção é essencial na visão marxista de história, ele destaca também que a passagem de um modo de produção a outro é uma passagem difícil: "Não se realiza automaticamente, em decorrência de movimentos cegos da economia” (Konder, 1984, p. 119). Em verdade, criar uma descontinuidade no modo de produção depende de iniciativas políticas e ações humanas. Além disso, Konder alude a Marx ao salientar que o que se passa na esfera política não é jamais mero reflexo do que acontece na esfera da economia: a esfera política dispõe de uma autonomia que não pode ser ignorada. Assim, convém lembrar que o movimento contrário também acontece; qual seja, as decisões políticas, 
principalmente aquelas que envolvem o Estado, acionam processos sociais que reverberam na economia, tema muito atual no cenário político brasileiro.

O ponto que queremos ressaltar no que diz respeito à perspectiva de uma crítica da economia política marxista é aquele que se refere à análise das relações humanas que se engendram sob o capitalismo. Na vertente desenvolvida por Marx e analisada por Konder, é preciso se preocupar seriamente com a criação concreta, por meio da luta política, de bases sociais para que sentimentos positivos, de ordem individual e coletiva, pudessem se desenvolver, como a solidariedade. De fato, a vida das pessoas, privada de uma dimensão comunitária concreta, ficou marcada pela insegurança e pelo isolamento. Desse modo, as relações reais dos indivíduos uns com os outros, em lugar de enriquecê-los, passam a se realizar por uma competição desmedida (Konder, 1984).

Na concepção dialética de história formulada por Marx, Konder (1984) põe em evidência o argumento de que não se exclui o contingente e o casual. Ao contrário, ele afirma que, no pensamento marxista, o acaso parece ser dimensão incontornável da história, posto que se reconhece a infinita riqueza da realidade e a constante possibilidade de surgimento do novo e do inédito nos horizontes da história. Contudo, a tese que se destaca no pensamento de Konder (1984) é aquela de que "Marx não concebia coisa alguma fora da história" e complementa com a seguinte assertiva: "a história é resultado da ação dos próprios homens e do movimento decorrente das iniciativas dos homens" (Konder, 1984, p. 123).

Em verdade, a crise atual do modelo capitalista nos incita a reexaminar Marx e as ideias fundamentais da dialética. Nesse reexame sua concepção de história nos surpreende com o vigor necessário ao processo da realização de transformações sociais. Nessa linha de interpretação, Konder ressalta a tese dialética capital advinda do pensamento de 
Hegel de que "A verdade é o todo" (Konder, 1984, p. 125). Deve-se, portanto, evitar os simplismos e reducionismos de esquematizações que privam o materialismo dialético de sua fecundidade.

Vale observar que, para Konder (1984), os melhores historiadores e pesquisadores são aqueles que, com frequência, são apaixonados, inquietos e que não recuam diante de obstáculos, e seus escritos não se detém em longas, áridas e muitas vezes exageradas digressões metodológicas. Constata-se nas obras analisadas (Konder, 1984; 1988; 1992; 2002) um manifesto destaque à categoria de "História" em que se evidencia o sentido dialético da integração entre as partes e o todo; a conexão que integra o micro e o macro e a interdependência entre singular e universal. Sobre essa base de compreensão, Konder (1992) assegura que Marx construiu os fundamentos de uma genuína "história social", à medida que articulava em suas obras a análise dos acontecimentos 104 políticos significativos com os movimentos da economia e da sociedade. Nessa vertente, ultrapassam-se os limites da análise conjuntural para um exame aprofundado das estruturas sociais. A complexidade do real desafia o pesquisador a se voltar para a história, por meio da abordagem do método dialético e a se aproximar do campo empírico e de algum processo histórico particular, forçando-o a ir além do empírico, isto é a teorizar. Como nas suas próprias palavras: "São os pormenores, quando nos deixamos surpreender por eles, que abrem a construção do nosso conhecimento para as revisões imprescindíveis ao reconhecimento da infinitude do real e a assimilação do novo" (Konder, 2002, p. 198).

\section{A história se repete como farsa...}

Com esse breve ensaio, esperamos ter mostrado alguns aspectos da relevância e atualidade do pensamento de Konder, principalmente se tivermos como pano de fundo histórico o nosso contexto de avanço 
da direita no mundo em geral e na América Latina em particular; mas, entrementes, sem perdermos de vista os vários movimentos de resistência e indignação. De fato, a obra de Konder está mais pertinente do que nunca, uma vez que vivemos, por um lado, um momento histórico de crise aguda do capitalismo, por outro, um considerável recrudescimento do pensamento marxista e do comunismo no Brasil e no mundo, uma espécie de (re)volta da dialética. Emblemática nesse sentido foi a conferência "The idea of communism", realizada em Londres, em março de 2009. Seus organizadores, entre eles os filósofos Slavoj Žižek e Alain Badiou, inicialmente reservaram uma sala com capacidade para 180 participantes no Birkbeck Institute for the Humanities, mas, ao final, tiveram que ocupar o auditório principal do Institute of Education, acomodando 900 pessoas, sem contar uma sala adjacente com telão de transmissão simultânea contendo mais 300 pessoas. As principais conferências do evento foram reunidas em livro homônimo The idea of communism (Douzinas e Žižek, 2010).

Outrossim, o pensamento de Konder pode e deve servir de inspiração para se repensar a derrota da esquerda (queda do Muro de Berlim) e a crise de 2008, sob uma perspectiva genuinamente dialética, bem como o atual contexto de golpe vivenciado na América Latina e no Brasil. A atualidade das ideias de Konder deve-se, sobretudo, ao modo original e perspicaz com que reflete sobre categorias ainda essenciais para compreendermos e transformarmos a realidade, tais como, práxis, ideologia, alienação, história, trabalho. Nós acreditamos que devemos revisitar a concepção konderiana de dialética, tendo como leitmotiv repensar a derrota da esquerda no plano de crise internacional e no contexto de golpe nacional, inspirados inclusive pela ocasião da efeméride de 80 anos do autor - que teria se tornado octogenário em 2016, caso não tivesse morrido em decorrência do 
"mal de Parkinson" em 2014 -, assim como pelos 30 anos de defesa de sua tese de doutorado que veio a ser publicada um ano depois, em 1988, sob o título justamente de $A$ derrota da dialética, quiçá sua obra-magna.

Não podemos nos furtar, por fim, de dizer que Konder publicaria, certamente, um texto por ocasião da comemoração dos cem anos da Revolução Russa, em 2017, como o fizera já em outras oportunidades. Podemos imaginar seu tom crítico dirigido contra os desvirtuamentos da era stalinista, sem deixar de saudar o ímpeto do espírito revolucionário originário. Decerto, ademais, ele erigiria uma reflexão arguta sobre o golpe atual, e, assim como o fez com relação ao golpe de 1964-68, não colocaria a "culpa" apenas na conta dos golpistas, senão faria novamente uma autocrítica pautada pelas perguntas "onde, como e por que erramos mais uma vez?". A frase de abertura dos "Agradecimentos" contidos em A derrota da dialética externa, claramente, a 106 motivação precípua de "acerto de contas":

A idéia de escrever sobre a história do marxismo no Brasil me veio à cabeça, pela primeira vez, nos meses que se seguiram imediatamente ao golpe de Estado de $1^{\circ}$ de abril de 1964, como parte do esforço para compreender por que a esquerda avaliara tão mal a situação e fora derrotada (Konder, 1988).

Estamos convictos de que, apesar da derrota para o golpe da caneta (sem precisar ter sido o da baioneta como o de outrora), ele estaria entusiasmado pelo otimismo da vontade adveniente das flores que brotaram pós primavera do Junho de 2013: ocupações dos estudantes, recrudescimento do movimento feminista, protagonismo dos movimentos por moradias, entre outras (re)voltas dialéticas antissistema. Movimentos esses que estão inseridos no contexto mais amplo de uma nova utopia de indignação e esperança ao redor do 
mundo. Isso tudo duas décadas e meia após Fukuyama e os neoconservadores ideólogos do neoliberalismo terem, de modo arrogante e apressado, vaticinado o "fim da história".

\section{André Luis de Oliveira Mendonça}

é doutor em Filosofia e professor adjunto do Instituto de Medicina Social (IMS) da Universidade Estadual do Rio de Janeiro (Uerj), tendo realizado pesquisa de pós-doutorado em Saúde Coletiva no mesmo Instituto.

\section{Katia Reis De Souza}

é doutora em Saúde Pública e pesquisadora do Centro de Estudos da Saúde do Trabalhador e Ecologia Humana (Cesteh), Escola Nacional de Saúde Pública (Ensp) da Fundação Oswaldo Cruz (Fiocruz).

\section{Bibliografia}

ALAMBERT, F. 2002. Melancolia e humor ou o fantástico revitalizador da dialética. In: PINASSI, M. O. (org.). Leandro Konder: a revanche da dialética. São Paulo: Boitempo/Unesp, 2002, pp. 115-125.

COUTINHO, C. N. 2002. Um filósofo democrático. In: PINASSI, M. O. (org.). Leandro Konder: a revanche da dialética. São Paulo: Boitempo/ Unesp, 2002, pp. 15-28.

DOUZINAS, C.; ŽIŽEK, S. 2010. The idea of communism. New York: Verso. GRAMSCI, A. 1986. Concepção dialética da história. Rio de Janeiro:

Civilização Brasileira. 2000. Cadernos do cárcere. v. 2. Rio de Janeiro: Civilização Brasileira.

KONDER, L. 1984. O marxismo na batalha das idéias. Rio de Janeiro: Nova Fronteira. 1988. A derrota da dialética. São Paulo: Campus. 1992. O futuro da filosofia da práxis: o pensamento de Marx no século

XXI. Rio de Janeiro: Paz e Terra. 2001. Limites e possibilidades de Marx e sua dialética para a

leitura crítica da história neste início de século. In: FRIGOTTO, G.;

CIAVATTA, M. (orgs.). Teoria e educação no labirinto do capital. Petrópolis: Vozes, 2001, pp. 98-114. 2002. A questão da ideologia. São Paulo: Companhia das Letras. 2004. O que é dialética. 28. ed. São Paulo: Brasiliense. 
2008. Memórias de um intelectual comunista. Rio de Janeiro:

Civilização Brasileira.

2010. Em torno de Marx. São Paulo: Boitempo.

KOSIK, K. 2010. Dialética do concreto. 7. ed. Rio de Janeiro: Paz e Terra.

LUKÁCS, G. 2012. História e consciência clássica: estudos sobre a dialética marxista. 2. ed. São Paulo: Martins Fontes. 2015. Reboquismo e dialética: uma resposta aos críticos de história e consciência de classe. São Paulo: Boitempo.

MARX, K. 2013. O capital: livro I. São Paulo: Boitempo.

MARX, K.; ENGELS, F. 1986. A ideologia alemã. 5. ed. São Paulo: Hucitec.

PINASSI, M. O. 2002. Leandro Konder: a revanche da dialética. São Paulo:

Boitempo/Unesp.

SECCO, L. 2002. Leandro Konder: leitor de Gramsci. In: PINASSI, M. O. (org.). Leandro Konder: a revanche da dialética. São Paulo: Boitempo/ Unesp, 2002, pp. 103-114. 


\section{A (RE)VOLTA DA DIALÉTICA: DIÁLOGO, AUTOCRÍTICA E TRANSFORMAÇÃO NO PENSAMENTO DE LEANDRO KONDER}

ANDRÉ LUIS DE OLIVEIRA MENDONÇA

KATIA REIS DE SOUZA

Resumo: Neste ensaio, defendemos a tese da relevância e atualidade do pensamento de Leandro Konder, tendo como foco principal sua concepção de dialética. Sendo aqui compreendida primordialmente como diálogo, autocrítica e transformação, extraímos a conclusão de que a dialética konderiana deveria nos inspirar a pensarmos e transformarmos o atual contexto de avanço da direita no mundo em geral e na América Latina e Brasil em particular, principalmente porque ao mesmo tempo já há, inegavelmente, uma espécie de (re)volta da dialética no sentido do recrudescimento da teoria social marxista e dos movimentos sociais antissistema, justamente duas décadas e meia após o precipitado e presunçoso decreto do "fim da história”.

Palavras-chave: Leandro Konder; Dialética; Diálogo; Autocrítica; Transformação.

\section{THE RETURN OF DIALECTIC: DIALOGUE, SELF-CRITICISM AND TRANSFORIMAIION IN LEANDRO KONDER'S THOUGHTS}

Abstract: In this essay, we support the thesis of the importance and currentness of Leandro Konder's thoughts, aiming its conception of dialectic. Here, it is mainly understood as dialogue, selfcriticism and transformation. We draw the conclusion that the 'konderiana' dialectic should inspire us to think and transform the current context of the overall right wing political party advance, mainly in Latin America and Brazil. Since there is undeniably, at the same time, a kind of return of the dialectic, in terms of recrudescence of Marx's theory and social movements, two and 
Resumos | Abstracts

half decades just after the abrupt and presumptuous decree of the "end of the history".

Keywords: Leandro Konder; Dialectic; Dialogue; Self-criticism; Transformation.

Recebido: 07/05/2017 Aprovado: 04/08/2017 